\title{
Knowledge and attitude of physicians for the diagnosis and management of obstructive sleep apnea
}

\author{
๑İbrahim Güven Çoşğun ${ }^{1}$, @Şule Çilekar¹, ๑Aydın Balc1 ${ }^{1}$, ๑Ersin Günay² \\ ${ }^{1}$ Afyonkarahisar Health Sciences University, Department of Pulmonology, Afyonkarahisar, Turkey \\ ${ }^{2}$ Yüksek İhtisas University, Faculty of Medicine, Department of Pulmonology, VM Medical Park Hospital, Ankara, Turkey
}

Cite this article as: Coşğun İG, Çilekar Ş, Balcı A, Günay E. Knowledge and attitude of physicians for the diagnosis and management of obstructive sleep apnea. J Health Sci Med 2021; 4(6): 790-794.

\begin{abstract}
Introduction: Obstructive sleep apnea (OSA) is a disease characterized by recurrent complete (apnea) or partial (hypopnea) upper respiratory tract obstructions episodes during sleep and often a decrease in blood oxygen saturation. The knowledge and attitude of physicians about OSA is very important as it influences the level of clinical suspicion of OSA which can lead to diagnose. Therefore, aim of this study was to evaluate the knowledge of and attitude to OSA of physicians.

Material and Method: This descriptive, cross-sectional survey study included 105 physicians in a university hospital. Participants completed the Obstructive Sleep Apnea Knowledge and Attitudes (OSAKA) questionnaire through the face-toface interview method.

Results:The study respondents comprised 55 (52.8\%) males and 50 (47.6\%) females with a mean age of $34.4 \pm 7.3$ years (range, 23-59 years). The years of experience was mean 10.45 \pm 7.37 years (range, 1-35 years). The knowledge level of physicians was mean score of $11.56 \pm 2.70$ (64.1\%). Attitude section, the mean score was $16.34 \pm 2.47$ from a possible maximum of 25 . A positive correlation was determined between the knowledge and the attitude scores of the physicians ( $r: 0.467 p<0.001)$.

Conclusion: These findings suggest that importance of the level of knowledge of physicians about OSA for early diagnosis and provision of treatment.
\end{abstract}

Keywords: Obstructive sleep apnea, physician, knowledge, attitude, survey, questionnaire, assessment

\section{INTRODUCTION}

Obstructive sleep apnea (OSA) is a disease characterized by recurrent complete (apnea) or partial (hypopnea) upper respiratory tract obstructions episodes during sleep and often a decrease in blood oxygen saturation (1). OSA is most common type of sleep-related breathing disorder (2). As a consequence of increasing obesity rates in the general population, the frequency of OSA is also rising (3). Untreated OSA causes cardiovascular diseases, decreases cognitive functioning, glucose intolerance and leads to metabolic diseases (4-7). OSA is an independent risk factor for developing hypertension (8). Daytime tiredness resulting from OSA may also cause traffic accidents resulting in morbidity and mortality (9).

Obstructive sleep apnea is quantified by the apneahypopnea index (AHI), which reflects the number of apneas and hypopneas per hour. Apnea-hypopnea index is derived after scoring data obtained using multi- channel polysomnography (PSG). PSG is considered the gold standard method for diagnosing OSA (10). Many individuals worldwide suffer from undiagnosed OSA (11). At $\geq 5$ events/h apnea-hypopnea index (AHI), the overall population prevalence ranged from $9 \%$ to $38 \%$ and was higher in men (12). OSA is affecting nearly $9 \%$ of women and $24 \%$ of men in the general middle-aged population (13). Studies have suggested that educational interventions for physicians are needed to improve the identification and treatment of patients with OSA (14). The knowledge and attitude of physicians about OSA is very important as it influences the level of clinical suspicion of OSA which will lead to diagnose. The knowledge level and attitude of physicians about OSA and it has been emphasized that these differences affect the management of OSA (15-17). This study aims to evaluate the knowledge and attitude of physicians about obstructive sleep apnea. 


\section{MATERIAL AND METHOD}

This study was designed as a prospective, descriptive, cross-sectional questionnaire study, which was conducted in Afyonkarahisar Health Sciences University Medical Faculty hospital between February 2020 and April 2020.

\section{Ethical Approval}

Approval for this study was granted by the Clinical Researchs Ethics Committee of Afyonkarahisar Health Sciences University (Date: 07.02.20, Decision No: 2020/2 KAEK-2). All procedures were carried out in accordance with the ethical rules and the principles of the Declaration of Helsinki.

\section{Sampling and Data Collection}

The study included 105 physicians who worked in Afyonkarahisar Health Sciences University Medical Faculty Hospital and agreed to participate. In face-toface interviews, the study participants completed the Obstructive Sleep Apnea Knowledge and Attitudes (OSAKA) questionnaire. The OSAKA questionnaire was developed by Schotland and Jeffe to evaluate the knowledge and attitudes of physicians about OSA syndrome (OSAS) (18). In a study of medical faculty students by Çelik, the Turkish version of the OSAKA questionnaire was determined to be a valid measurement tool with Turkish translation and cultural adaptation according to the criteria of Guillemin et al $(19,20)$.

The OSAKA questionnaire consists of 18 items measuring the level of knowledge of OSAS, and 5 items to evaluate attitudes to OSAS (Table 1). The items which measure the level of knowledge include questions related to epidemiology, pathophysiology, symptoms, diagnosis and treatment, which are answered with 3 options of "true", "false", and "I don't know". The response of "I don't know" is accepted as false. In the calculation of the total knowledge points, a correct response is scored with 1 point and false or I don't know with 0 points. The total points are divided by 18 to provide a percentage. Of the 5 items evaluating attitudes to OSAS, the first 2 items are related to the clinical importance of OSAS. The reponse to these items are scored on a 5-point Likert-type scale from 1 (not important) to 5 (extremely important) (not important $=1$, somewhat important $=2$, Important $=3$, very important $=4$, extremely important $=5$ ). The other 3 items are related to confidence about diagnosis and treatment, with response scored from 1 (I strongly do not agree) to 5 (I strongly agree) (strongly disagree $=1$, disagree $=2$, neither agree nor disagree $=3$, agree $=4$, strongly agree $=5$ ). The demographic characteristics of the study participants were recorded.
Table 1. The obstructive sleep apnea knowledge questionnaire

1 . Women with obstructive sleep apnea may present with fatigue only.

2. Uvulopalatopharyngoplasty is curative for a majority of people with obstructive sleep apnea.

3. The estimated prevalence of obstructive sleep apnea among adults is between $2 \%$ and $10 \%$.

4. The majority of patients with obstructive sleep apnea snore.

5. Obstructive sleep apnea is associated with hypertension.

6. An overnight sleep study is the gold standard for diagnosing obstructive sleep apnea.

7. CPAP (continuous positive airway pressure) therapy may cause nasal obstruction.

8. Laser-assisted uvuloplasty is an appropriate treatment for severe obstructive sleep apnea.

9. The loss of upper airway muscle tone during sleep contributes to obstructive sleep apnea.

10. The most common cause of obstructive sleep apnea in children is the presence of large tonsils and adenoids.

11. A craniofacial and oropharyngeal examination is useful in the assessment of patients with suspected obstructive sleep apnea.

12. Alcohol at bedtime improves obstructive sleep apnea.

13. Untreated obstructive sleep apnea is associated with a higher incidence of automobile crashes.

14. In men, collar size 17 inches or greater is associated with obstructive sleep apnea.

15. Obstructive sleep apnea is more common in women than in men.

16. CPAP is the first-line therapy for severe obstructive sleep apnea.

17. Fewer than 5 apneas or hypopneas per hour is normal in adults.

18. Cardiac arrhythmias may be associated with untreated obstructive sleep

\section{Statistical Analysis}

Data obtained in the study were analyzed statistically using IBM SPSS 25 software (IBM Corpn., Armonk, NY, USA). Descriptive statistics of the data were stated as mean \pm standard deviation values. Conformity of the data to normal distribution was assessed with the KolmogorovSmirnov test. In the analysis of independent quantitative data, the Mann Whitney U-test was used, and for the analysis of qualitative independent data, the Chi-square test was applied. A value of $\mathrm{p}<0.05$ was accepted as statistically significant. It was determined that a sample size of 84 was required to represent the population, with a sampling error of $5 \%$ at a $80 \%$ power.

\section{RESULTS}

The 105 physicians included in the study comprised 55 (52.8\%) males and 50 (47.6\%) females with a mean age of 34.4 \pm 7.3 years (range, $23-59$ years). The mean years of experience were recorded $10.45 \pm 7.37$ years (range, $1-35$ years). The demographic data of the study participants are shown in Table 2. 


\begin{tabular}{|lcc|}
\hline \multicolumn{3}{|l|}{ Table 2. Sociodemographic characteristics of the participants } \\
\hline $\begin{array}{l}\text { Socio-demographic } \\
\text { characteristics }\end{array}$ & $\begin{array}{c}\text { Frequency. n (\%) } \\
\mathbf{n}=\mathbf{1 0 5}\end{array}$ & Mean (SD) \\
\hline $\begin{array}{l}\text { Age (year) } \\
\text { Years of Experience }\end{array}$ & $34.4 \pm 7.3$ \\
Men & $55(52.8 \%)$ & $10.45 \pm 7.37$ \\
Women & $50(47.6 \%)$ & \\
\hline
\end{tabular}

\section{OSAS Knowledge Level}

The mean score of the OSAKA responses for the knowledge section was $11.56 \pm 2.70 \quad(64,1 \%)$. The knowledge section points are shown in Table 3. No statistically significant difference was determined between the mean knowledge points of males $(11.67 \pm 2.86$, $64,7 \%$,$) and females (11.44 \pm 2.54,63,4 \%)(\mathrm{p}=0.056)$. No statistically significant difference was determined between the years of professional experience and the knowledge points $(p>0,05)$. The percentages of true and false responses in the knowledge category of the OSAKA questionnaire are shown in Figure 1. The highest rate of correct responses (92\%) was given to the item, "untreated OSAS is associated with an increased incidence of traffic accidents". The lowest rate of correct responses (20\%) was given to the item, "uvulopalatopharyngoplasty is curative in most OSAS patients".

\begin{tabular}{|lcc|}
\hline \multicolumn{3}{|c|}{ Table 3. Knowledge scores of participants regarding OSA } \\
\hline \multicolumn{1}{|l|}{ Knowledge Score, $\mathbf{N}$} & $(\%)$ & Mean (SD) \\
\hline Gender & & \\
Men (n:55) & 64.76 & $11.67 \pm 2.86$ \\
\hline Women (n:50) & 63.49 & $11.44 \pm 2.54$ \\
\hline
\end{tabular}

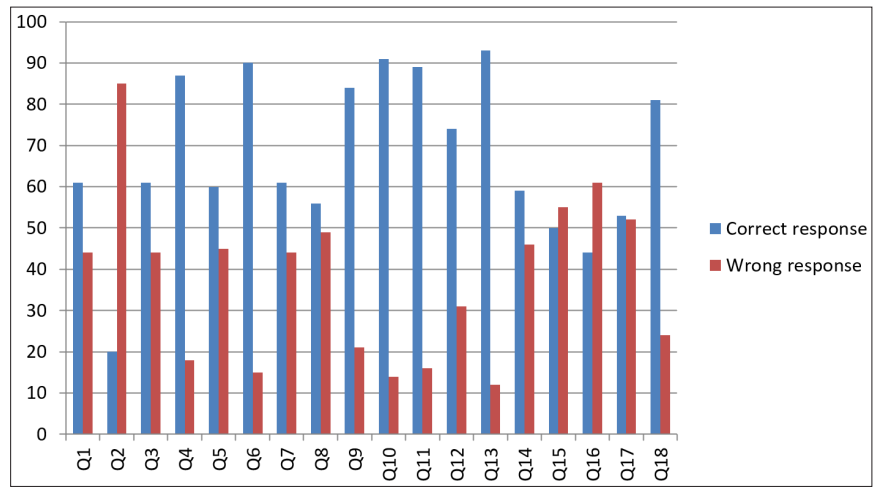

Figure 1. The frequency and percent of correct responses to questions on knowledge among the participants regarding OSA

\section{OSAS Attitude Level}

In the attitude section of the OSAKA questionnaire, the mean score was $16.34 \pm 2.47$ from a possible maximum of 25 . The highest points were determined in response to the item, "OSAS is important as a clinical disorder", to which $72 \%$ of the respondents stated that it was very important and extremely important. The lowest points (23\%) were in reponse the item "I am confident in my management of patients receiving CPAP".

\section{Correlation between the Knowledge and Attitude Levels}

A moderate level positive correlation was determined between the knowledge and the attitude scores of the respondents ( $\mathrm{r}: 0.467 \mathrm{p}<0.001)$.

\section{DISCUSSION}

The level of knowledge and attitudes of physicians to OSAS were evaluated in this study. In this study, the total correct mean knowledge score was $64 \%$. Physicians do not routinely engage in formal postgraduate training programs. The level of physicans knowledge at the time of graduation from medical school affect the quality of their practice after graduation. In a study by Schotland and Jeffe (18), who developed the OSAKA questionnaire, the level of knowledge of physicians in a university hospital in the USA was determined to be $76 \%$. Wang et al. (21) measured the level of knowledge of anesthesia specialists in China and reported a score of $62 \%$, while in another study of anesthesia specialists in Italy, the knowledge level score was found to be $66 \%$ (22). In a study by Deveraj (23) in Kuala Lumpur, the knowledge level score was determined to be $64.38 \%$ for primary level physicians in healthcare clinics treating inpatients and outpatients. Medical Faculty students in Nigeria were evaluated in another study and the knowledge level score was found to be $42 \%$ (24). In a previous study in Turkey, the knowledge level score of medical faculty students was reported to be $61 \%$ (19).

The score for the level of knowledge obtained in the current study was seen to be lower than that of the study by Schotland and Jeffe. In this study level of knowledge was similar to the scores reported by Wang and Deveraj and the study of medical faculty students in Turkey. Our results was higher than that of the medical faculty students in Nigeria. In the study by Schotland and Jeffe (18), a negative correlation was observed between age and the knowledge level score. No such correlation was determined in the current study, and there was no correlation between the years of professional experience and knowledge level. Furthermore, consistent with the findings of previous studies, there was no statistically significant difference in the knowledge level scores according to gender.

Within the items related to attitude, $72 \%$ of the respondents in the current study stated that OSAS was very important or extremely important as a clinical disorder. This response rate was determined to be higher compared to the study by Deveraj (23) (59\%) and similar to the rates reported by Southwell (17) (68\%) and Ojeda et al. (25) (72\%). In the previous study of Turkish medical students, this rate was found to be $79 \%$ (18). Of the current study 
participants, $21 \%$ stated that they were comfortable with their management of OSAS patients, which was similar to the result of the study by Deveraj (23\%). In that same study, $7 \%$ of the primary level physicians were confident in their management of CPAP treatment, while this rate was found to be $23 \%$ in the current study. The responses of primary level physicians to the same question were determined to be $22 \%$ by Ojeda et al. (25) and $26 \%$ by AlKhafaji et al. (16). This rate was determined as $21,3 \%$ in the study of Turkish medical students (19). The confident in their management of CPAP obtained in the current study was seen to be similar to the previusly studies.

Previosly studies have demonstrated that the positive correlation between knowledge and attitude scores. AlKhafaji (16) found that primer care physicians have weak level correlation ( $\mathrm{r}: 0.142)$. Medical Faculty students in Nigeria have weaklevel correlation ( $(\mathrm{r}: 0.142)(24)$. Solanski (14) and Corso (22) evaluated anesthesia specialists they found moderate correlation (respectively r:0.37; r:0.40). In a previous study in Turkey, correlation level of medical faculty students was reported weak (r:0.156) (19). Our results ( $r: 0.467)$ was higher than that medical faculty students, similar that anesthesia specialists. The positive correlation between knowledge and attitude scores suggests that physicians with a better understanding of OSA-related problems are more confident in selecting the safest method for its management.

\section{Limitations}

This study had some limitations. The findings of this study must be interpreted in light of its limitations. First this was a cross-sectional survey of physicians in a university hospital.

Study group was formed only of physicians in a university hospital, and so there was a relatively low number of participants. Thus, we cannot infer causation from any of the associations we observed, and we also cannot generalize our results to physicians. It is a cross-sectional study and cannot establish the causal relationship between low knowledge and low education programs. Other potential factors, not assessed in this study, that may have influenced responses include the specialization and access to sleep specialists and sleep laboratories. However, a strong aspect of the study was that to avoid systematic prejudice, the questionnaires were completed in face-to-face interviews.

\section{CONCLUSION}

The knowledge and attitudes about OSAS of physicians in a university hospital were evaluated in this study. The results demonstrated a positive correlation between the knowledge level scores and the attitude scores. Although the knowledge and attitude levels were seen to be similar to those reported in previous studies, they were not at the expected level. This likely contributes to the rate of OSA underdiagnosis. Management of patients with OSA is linked to a variety of factors, including the personal knowledge, clinical experience. The results of this study emphasize the importance of the level of knowledge of physicians about treatment options for OSA for early diagnosis and provision of treatment to be able to bring the disease under control. Physicians need to enhance awareness of OSA. Education of OSA for physicians need to improve knowledge and management of this important and prevalent disorder.

\section{ETHICAL DECLARATIONS}

Ethics Committee Approval: Approval for this study was granted by the Clinical Research Ethics Committee of Afyonkarahisar Health Sciences University (Date: 07.02.20, Decision No: 2020/2 KAEK-2).

Informed Consent: Informed consent was obtained from all individual participants included in the study.

Referee Evaluation Process: Externally peer-reviewed.

Conflict of Interest Statement: The authors have no conflicts of interest to declare.

Financial Disclosure: The authors declared that this study has received no financial support.

Author Contributions: All of the authors declare that they have all participated in the design, execution, and analysis of the paper, and that they have approved the final version.

Acknowledgments: The authors thanks Medical Faculty Student Fatih Sarı, Kadir Can İlhan, Semih Sarı, Onuralp Özalp, Elif Sevim, Hilal Ergün for contributions this study.

\section{REFERENCES}

1. Roeder M, Sievi NA, Kohler M, Schwarz EI. Predictors of changes in subjective daytime sleepiness in response to CPAP therapy withdrawal in OSA: A post-hoc analysis. J Sleep Res 2021; 30: e13078.

2. Meszaros M, Tarnoki AD, Tarnoki DL, et al. Obstructive sleep apnea and hypertriglyceridaemia share common genetic background: Results of a twin study. J Sleep Res 2020; 29: e12979.

3. Flegal KM, Carroll MD, Ogden CL, Johnson CL. Prevalence and trends in obesity among US adults. JAMA 2002; 288: 1723-7.

4. Alaçam Z, Pekcan S, Akdağ B, Şenol H. The Relationship of hemogram parameters and night desaturation in patients diagnosed with obstructive sleep apnea syndrome. J Turk Sleep Med 2018; 5: 62-6.

5. Dursunoglu D, Dursunoglu N. Cardiovascular diseases in obstructive sleep apnea. Tuberk Toraks 2006; 54: 382-96.

6. Zhang RH, Zhao W, Shu LP, et al. Obstructive sleep apnea is associated with coronary microvascular dysfunction: A systematic review from a clinical perspective. J Sleep Res 2020; 29: e13046.

7. Alvarez-Sabín J, Romero O, Delgado P, et al. Obstructive sleep apnea and silent cerebral infarction in hypertensive individuals. J Sleep Res 2018; 27: 232-9. 
8. Floras JS. Hypertension and sleep apnea. Can J Cardiol 2015; 31: 889-97.

9. Turkington PM, Sircar M, Allgar V, Elliott MW. Relationship between obstructive sleep apnoea, driving simulator performance, and risk of road traffic accidents. Thorax 2001; 56: 800-5.

10. Escourrou P, Grote L, Penzel T, et al. ESADA Study Group. The diagnostic method has a strong influence on classification of obstructive sleep apnea. J Sleep Res 2015; 24: 730-8.

11. Young T, Evans L, Finn L, Palta M. Estimation of the clinically diagnosed proportion of sleep apnea syndrome in middle-aged men and women. Sleep 1997; 20: 705-6.

12. Senaratna CV, Perret JL, Lodge CJ, et al. Prevalence of obstructive sleep apnea in the general population: A systematic review. Sleep Med Rev 2017; 34: 70-81.

13. Young T, Palta M, Dempsey J, Skatrud J, Weber S, Badr S. The occurrence of sleep-disordered breathing among middle-aged adults. N Engl J Med 1993; 29; 328: 1230-5.

14. Solanki SL, Karan N, Parab SY. Obstructive sleep apnoea and its knowledge and attitude among Indian anaesthesiolgists - A survey study. Indian J Anaesth 2019; 63: 648-52.

15. Ozoh OB, Iwuala SO, Desalu OO, Ojo OO, Okubadejo NU. An assessment of the knowledge and attitudes of graduating medical students in Lagos, Nigeria, regarding obstructive sleep apnea. Ann Am Thorac Soc 2015; 12: 1358-63.

16. Al-Khafaji H, Bilgay IB, Tamim H, Hoteit R, Assaf G. Knowledge and attitude of primary care physicians towards obstructive sleep apnea in the Middle East and North Africa Region. Sleep Breath 2021; 25: 579-85.

17.Southwell C, Moallem M, Auckley D. Cardiologist's knowledge and attitudes about obstructive sleep apnea: a survey study. Sleep Breath 2008; 12: 295-302.

18. Schotland HM, Jeffe DB. Development of the obstructive sleep apnea knowledge and attitudes (OSAKA) questionnaire. Sleep Med 2003; 4: 443-50. Erratum in: Sleep Med 2008; 9: 705.

19. Çelik, M. An assessment of the knowledge and attitudes of medical students about obstructive sleep apnea syndrome via obstructive sleep apnea knowledge and attitudes questionnaire. KBB Uygulamaları 2020; 8: 89-96.

20. Guillemin F, Bombardier C, Beaton D. Cross-cultural adaptation of health-related quality of life measures: literature review and proposed guidelines. J Clin Epidemiol 1993; 46: 1417-32.

21. Wang CL, Li XZ, Cai XL, Pan XL, Min J. Anesthesiologist's knowledge and attitude about obstructive sleep Apnea: a survey study. Sleep Breath 2012; 16: 41-6.

22. Corso RM, Sorbello M, Buccioli M, et al. G. Survey of knowledge and attitudes about obstructive sleep apnoea among Italian anaesthetists. Turk J Anaesthesiol Reanim 2017; 45: 146-52.

23.Devaraj NK. Knowledge, attitude, and practice regarding obstructive sleep apnea among primary care physicians. Sleep Breath 2020; 24: 1581-90.

24. Ozoh OB, Iwuala SO, Desalu OO, Ojo OO, Okubadejo NU. An assessment of the knowledge and attitudes of graduating medical students in Lagos, Nigeria, regarding obstructive sleep apnea. Ann Am Thorac Soc 2015; 12: 1358-63.

25. Cherrez Ojeda I, Jeffe DB, Guerrero T, et al. Attitudes and knowledge about obstructive sleep apnea among Latin American primary care physicians. Sleep Med 2013; 14: 973-7. 